\title{
Architecture of Backpropagation Neural Network Model for Early Detection of Tendency to Type B Personality Disorders
}

\author{
Cynthia Hayat ${ }^{*}$, Samuel Limong, Noviyanti Sagala \\ Department of Engineering and Computer Science \\ Krida Wacana Christian University \\ Indonesia \\ "cynthia.hayat@ukrida.ac.id
}

\begin{abstract}
Personal disorder is a type of mental illness. People with personal disorder cannot respond changes and demands of life in normal ways. Women with type B personal disorder tend to have high risk of violence. It is important to make early detection of this personal disorder, so that it can be anticipated properly. This paper reports an architecture model of back propagation neural network (BPPN) for early detection of type B personal disorder. The back propagation process divided into two phases, training and testing. The training process used 43 data and the testing process used 34 data. The output classified into 4 diagnosis categories of type B personal disorder, namely: anti-social, borderline, histrionic, and narcissistic. The optimal parameters of BPPN model consist of maximum epoch of 1000 , maximum mu of 10000000000 , increase mu of 25 , decrease mu of 0.1 , and neuron hidden layer of 25 . The MSE of training is 3.07E-14 and MSE of testing is $1.00 \mathrm{E}-03$. The accuracy of training is $90.7 \%$, while the accuracy of testing is $97.2 \%$.
\end{abstract}

Keywords: back propagation, early detection, neural network, personality disorders

\section{Introduction}

Mental Health of America defines personality disorder as a setback that occurs in the internal and external of the human self where the person tends to be inflexible, rigid and unable to respond to changes and the demands of life [1]. Meanwhile, according to Diagnostic and Statistical Manual (DSM) IV, personality disorders are patterns of experience and inner behavior that deviate significantly and causing disorder. [2]

The both definitions refer to the inflexibility of behavior patterns in thought so that it can produce an impact on personal social life. A study by Danie Martin de Barros and Antonio de Pádua Serafim, stated that personality disorders of antisocial and borderline are highly predicted to make violence [3]. Research conducted by Riikka Arola et al., found that borderline personality disorder is a factor of violence attacks by women [4].

Early detection of personality disorder is needed so that it can be anticipated properly. The lack number of experts in the field of clinical psychology causing difficulties for people to obtain the information, therapy, and treatment that they should have. Through this research, with the application of artificial neural networks, it is expected to be able to construct a modeling to initiate early diagnosis of the type B personality disorder tendency. Artificial Neural Network (ANN) is a concept of artificial knowledge in the field of artificial intelligence that made by adopting the human nervous system in the brain. In the journal Disease-Free Survival Assessment by Artificial Neural Networks for Hepatocellular Carcinoma Patients after Radio Frequency Ablation [5] stated that the artificial neural network model can recognize patterns of data through the learning process and has been applied to attain medical decision support. The study conducted by Panpan $\mathrm{Hu}$ stated that artificial neural networks can be used to analyze patterns of psychological patients, where the ANN model developed has a high accuracy training level with an average of $98.2 \%$. ANN has a good training ability with a sufficient prediction level and the method can support in determining the diagnosis based on the results of the analysis [6]. Elvia Budianita and Muhammad Firdaus reported the method of artificial neural networks use Learning Vector Quantization 2 (LVQ2) in diagnosing psychiatric illnesses in which has a good accuracy of $90 \%$ [7]. While Tri Nur Oktavia et.al, reported the expert system in diagnosing hysterical personality disorders. The results of the expert system are compared with the results of the experts with a percentage of accuracy of $83.01 \%$ [8]

The novelty of this study is the use of rule-based 
interviews with the experts as input data during the training phase. And it is projected that this research can contribute to the discipline of clinical psychology by providing the results of analysis and diagnosis of type $B$ personality disorder, so that preventive action can be taken as early as possible.

\section{Research Methodology}

\section{a. BPNN Procedures}

The procedure for developing the proposed BPNN model is as follows:

Step 1: Data preparation, conducted by collecting the necessary data. Data collection is performed in 2 ways, by collecting primary data and collecting secondary data. Primary data obtained from expert rule-based data. Whereas secondary data obtained from observation women at a Hospital in Jakarta and also through semi-structured interviews with experts, some psychiatric doctors and psychologists.

Step 2: Constructing a decision tree and rule based on the decision tree. Constructing rule-based is performed using if-then rules as in the expert system. Constructing a rule is based on data that has been collected.

Step 3: Training Stage: Symptom data will be analyzed to be the result of back propagation neural network training. Data from the analysis of symptoms are in the form of input data and output data which will become training data for artificial neural network architecture. The training data utilize the calculation of the average value to get the target value. The training process with a separate target value used for artificial neural networks can recognize each personality disorder separately [9]. The results of the training will be used to predict the tendency for personality disorders.

Step 4: The input value is changed to a random value with a range $[0,1]$. Inputs used in the system are data of symptoms that have been represented in the numerical form with variables 0 (No) and 1 (Yes).

Step 5: Determining the activation function and parameters used in the BPNN model. The activation function is used to control the output value to match a predetermined one. In this model, the activation function is binary sigmoid. Iteration will be stopped if the maximum value of the epoch is 1000,3000 , and 5000 , the error goal is 0 , the mean square error is close to 0 and the result of regressions is close to 1 .
Step 6: Determining the number of hidden layer neurons from 1 hidden layer used. Hidden layer neurons are determined by trial and error, which means that the fastest and most precise learning outcomes will determine the number of hidden layer neurons. The variations in the number of hidden layer neurons used are 15, 25, and 35. The $\mathrm{Mu}$ Increase variations used are 5, 10, and 25 . The Mu Decrease variations are 0.05, 0.1, and 1. The training function is trainbr (Bayesian Regulation Back Propagation)

Step 7: Testing parameters in the BPNN model. Where the weight of ANN from the training phase will be implemented into the testing phase by inputting the symptoms.

Step 8: The output result is a type of personality disorder tendencies.

\section{b. Data Collection}

This research is a qualitative research as the symptoms of type B personality disorder are obtained from interviews and processed into ruled based. The research instrument is a tool for collecting data needed for research. The type of research instrument used was interviews. While quantitative data are questionnaires in the form of tendencies of personality disorder type B in respondents. Data is collected in two ways including:

1. Primary data, obtained from rule-based data based on interviews with experts.

2. Secondary data, data of observations and semistructured interviews conducted to two fields of expertise, psychiatric doctors and psychologists.

The data collection includes:

1) Type of Personality Disorders

Data of types of personality disorders are data according to the Diagnostic and Statistical Manual of Mental Disorders, presented in table 1. [2]

\begin{tabular}{cc}
\multicolumn{2}{c}{ Table 1. Data on type B of personality disorders } \\
$\begin{array}{c}\text { Target } \\
\text { Code }\end{array}$ & $\begin{array}{c}\text { Type of Personality Disorders } \\
\text { Type B }\end{array}$ \\
\hline T1 & Borderline \\
T2 & Antisocial \\
T3 & Narcissistic \\
T4 & Histrionic \\
\hline
\end{tabular}

The type B of personality disorders are classified into 4 types, as follows:

a) Antisocial is a pattern of ignorance, and violation of the rights of others.

b) Borderline is a pattern of instability in interpersonal relationships, self-image and marked by impulsiveness. 
c) Histrionic is a pattern of emotional and excessive attention.

d) Narcissistic is a pattern of grandeur, the need for admiration, and lack of empathy.

2) General Symptoms Data

General symptom data are symptom data that are visible and also felt by the patient [10]. General disorder data is presented in Table 2.

3) Type B Personality Disorder Symptoms Data

Personality disorder data are symptoms that are felt by the patient. These data are classified according to predetermined types of personality disorders. Data on personality disorders can be seen in Table 3 .

Table 2. General Symptoms Data

1 The ability to understand yourself, others and events are weak

2 Emotional frequency range to the weak emotions (too far)

3 Weak interpersonal function

4 Weak emotional control

5 Inflexible in various fields of social life

6 Social life between people both from various environments is not good

Table 3. Symptoms Data

\begin{tabular}{lll}
\hline No. & \multicolumn{1}{c}{ Symptoms } & \multicolumn{1}{c}{$\begin{array}{c}\text { Type of } \\
\text { Disorder }\end{array}$} \\
\hline G1 & Excessive imagination or avoidance of reality & Borderline \\
G2 & Pattern and intensity of unstable interpersonal relationships & \\
G3 & Unstable self-identity & \\
G4 & $\begin{array}{l}\text { Impulsive, at least in two areas that have the potential to self-destruct (shopping, sex, drug } \\
\text { abuse, careless driving, greedy) }\end{array}$ \\
G5 & Repeated suicidal behavior or behavior that hurts others/him/herself \\
G6 & Mood instability & \\
G7 & Chronic empty heart feeling \\
G8 & Emotions that are not in the atmosphere/difficult to control anger \\
G9 & Severe dissociative symptoms
\end{tabular}

G10 Often violates the norm Antisocial

G11 Lies often, likes to use aliases, deceives others for personal gain

G12 Impulsive when plans are not achieved

G13 Easy to have bad-tempered and aggressive, especially in physical fights

G14 Ignores the security of him/herself or others

G15 Ignores the security of him/herself or others

G16 Be indifferent

G17 Exaggerates achievements and talents, hoping to be recognized as superior without $\quad$ Narcissistic commensurate achievement

G18 Busy with fantasies of success, strength, brilliance, beauty, or unlimited love

G19 Believes that he/she is "special" and unique, only wants to be recognized with other people or special status (or institutions)

G20 Requires excessive admiration

G21 Has the feeling of excessive rights

G22 In exploitative inter-commercials, that is, utilizes other people to achieve their own goals

G23 Lack of empathy: do not want to recognize the feelings and needs of others

G24 Often envies others or believe that others envy him

G25 Shows arrogant behavior 


\begin{tabular}{lll}
\hline No. & \multicolumn{1}{c}{ Symptoms } & $\begin{array}{c}\text { Type of } \\
\text { Disorder }\end{array}$ \\
\hline G26 & Uncomfortable in a situation where she/he is not the center of attention & Histrionic \\
G27 & Interaction with others is often characterized by seductive and provocative sexual behavior & \\
G28 & Shows expressions of emotions that are fast shifting and superficial & \\
G29 & Consistently uses physical appearance to attract attention & \\
G30 & Has a style of speech that is too impressionistic and lacks detail & \\
G31 & Shows self-dramatization, theatrics, and excessive emotional expression \\
G32 & Predictable, i.e. easily influenced by other people or circumstances \\
G33 & Thinksof a more intimate relationship/wants more intimacy &
\end{tabular}

\section{c. Decision Tree \& Rule-based}

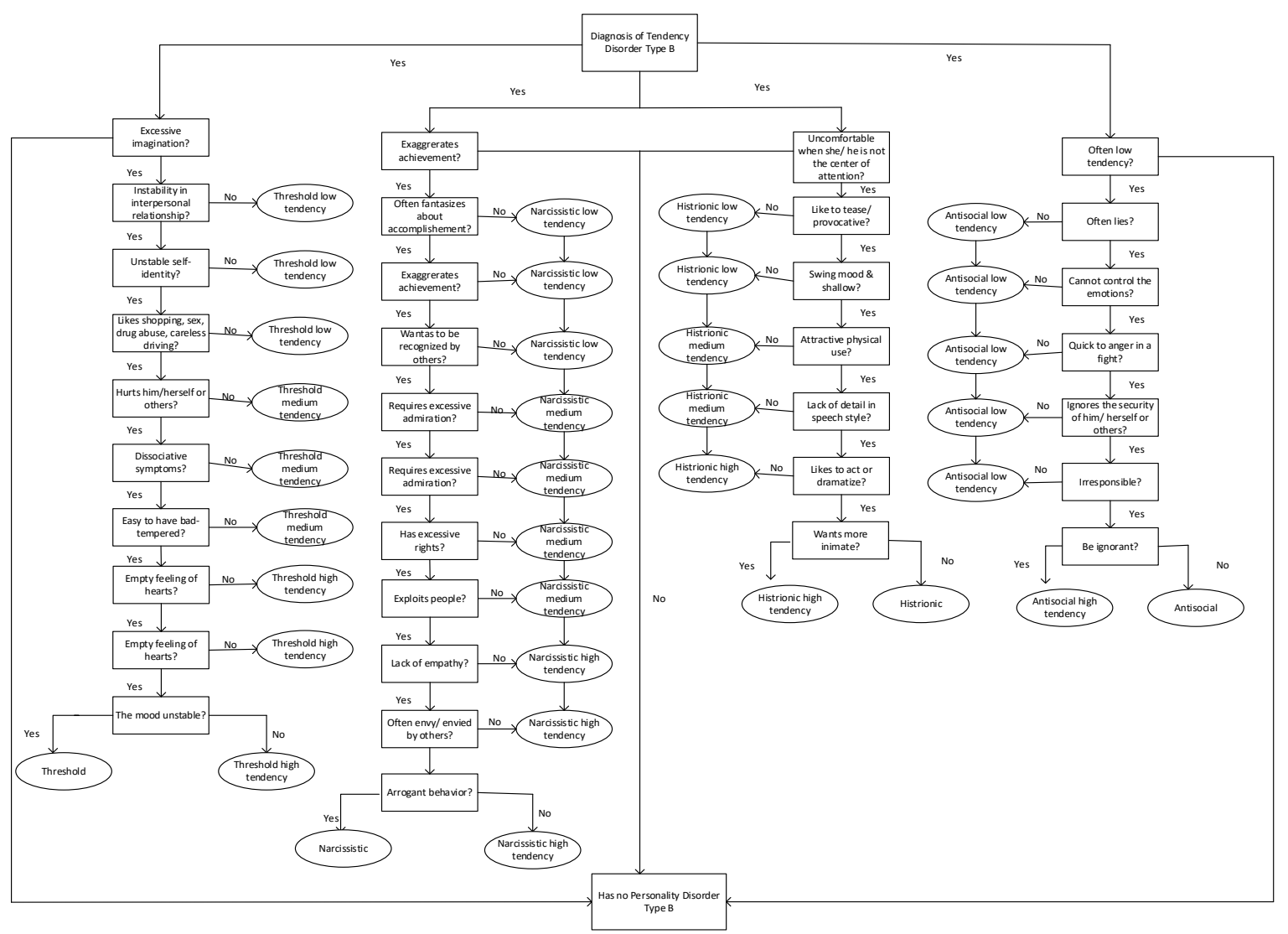

Figure 1. Decission Tree

The decision tree of symptoms and personality disorders is formulated as a tool in composing decisions (decision support tool) and identifying the relationship between the factors that influence a setback. Figure 1 illustrates the decision tree of symptoms and personality disorders.

The nodes in the decision tree are symptoms, while the bottom nodes are decisions. Furthermore, rule-based is made based on the decision tree. Rule-based construction will be used as an input layer in the architecture modeling of BPNN.

Rules-Based System

a) Rule 1

IF the ability to understand oneself, others and events is weak

OR the emotional frequency range in emotions is weak (too far)

OR the interpersonal function is weak

OR emotional control is weak

OR is not flexible in various fields of social life

OR social life between people from both different environments is not good

THEN checks for personality threshold/ antisocial/histrionic/narcissistic type

\section{ELSE}

THEN tends personality disorders

b) Rule 2: check borderline personality disorder IF excessive imagination/avoid reality 
OR unstable and intense patterns of marked interpersonal relationships that are unstable OR self-identity is unstable

OR is impulsive, at least in two areas that have the potential to self-destruct (shopping, sex, drug abuse, careless driving, greedy)

OR repeats suicidal behavior/behavior that hurts others or him/herself

OR mood instability

OR chronic empty feeling of heart

OR emotions that are not in the atmosphere/ difficult to control anger

OR severe diss-associative symptoms

THEN likelihood of borderline personality disorder

b) Rule 3: check personality disorders

IF often violates the norm

OR often lies, likes to use aliases, deceives others for personal gain

OR is impulsive when plans are not achieved

OR is quick to anger and aggressive, especially in physical fights

OR ignores the security of him/herself or others

$\mathbf{O R}$ is not responsible

OR be indifferent

THEN antisocial personality disorder tendencies

c) Rule 4: check narcissistic personality disorder

IF exaggerates achievement and talent, hoping to be recognized as superior without commensurate achievement

OR is preoccupied with fantasies of success, strength, brilliance, beauty, or infinite love

OR believes that he/she is "special" and unique, only wants to be recognized with other people or special status (or institutions)

OR requires excessive admiration

OR has a feeling of excessive rights

OR is exploitative inter-commercial, which is utilizing other people to achieve their own goals
OR Lack of empathy: do not want to recognize the feelings and needs of others

OR often envies others or believes that others envy them

OR shows arrogant behavior

THEN tendency for narcissistic personality disorder

d) Rule 5: check histrionic personality disorder

IF is uncomfortable in situations where it is not the center of attention

OR interactions with others are often characterized by seductive and provocative sexual behavior

OR displays emotional expressions that are fast shifting and superficial

OR consistently uses physical appearance to attract attention

OR has a speaking style that is too impressionistic and lacks in detail

OR shows excessive self-dramatization, theatrics, and emotional expression

$\mathbf{O R}$ is predictable, that is easily influenced by other people or circumstances

OR consider relationships more intimate/want more intimate

THEN tendency for histrionic personality disorder

\section{d. BPNN Architectural Model Design}

Artificial Neural Network is a form of innovative learning, statistical models that mimic neuronal functions, able to identify patterns and separate them linearly by providing weight values numeric input for each and adjust it to the data sample [11]. Artificial Neural Networks can use parallel processing to predict solutions to complex variable data. The design of the BPNN architecture model for early detection of personality disorder tendencies is shown in Figure 2.

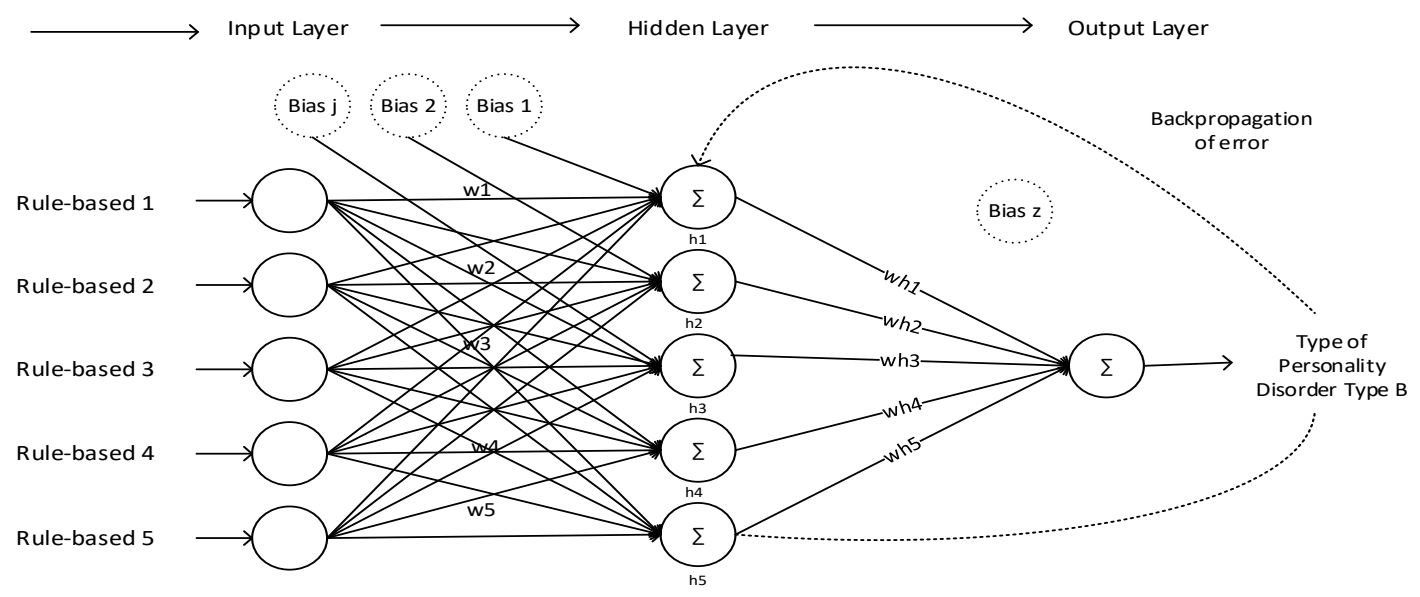

Figure 2 BPNN Architecture Model of Detection of Type B Personality Disorders 
The architecture consists of three layers: input layer, hidden layer, and output layer. The back propagation learning algorithm consists of three stages: forward propagation of input signals, back propagation of errors, and weighting of updates. By spreading the input signal to the front (output), the first back propagation algorithm calculates the output for each vector included in the training data set. The next process is modifying the weights of each input vector. An error in the output neuron spreads in the reverse direction from the output layer to the input layer [12]

\section{Discussion Results}

\section{a. Application of Artificial Neural Networks}

The symptoms obtained from experts are processed into the training data. The processing of symptoms data becomes an input parameter for the training process. Meanwhile, the output data are in the form of personality disorder type B. Input data scale is in the form of 0 and 1, 0 for not having these symptoms and 1 for those who have these symptoms. For the output in the form of a scale from 0 to 1 , the higher the value, the higher the tendency. In the target data, it is made into four targets, each of which represents symptoms of personality type $\mathrm{B}$.

The data training process is the first step conducted to determine training data to get the results of the training data. The stage of the training divided into several processes, as follows:

1) Establishing training data, training data are obtained from the processing of symptoms.

2) Determining the activation function, the number of hidden layers and the training function. Determining the number of hidden layers according to Jeff Haeton. Hidden layers can be determined based on the complexity of the application, the rules are as follows:

- Problems representing linear programs, so the number of hidden layers is only 0 .

- Problems representing functions that contain a mapping from space to another space, so the number of hidden layers is 1 .

- The problem represents that it can estimate all the mapping, then the number of hidden layers is 2 . For more than 2 hidden layers, learning automation is needed.

3) Entering the maximum variable epoch, a number of neurons, error goal, max fail, mu ins, and mu dec.

4) It is a process of trial and error (repeating until getting optimal results), if we get poor training results, then the variables entered into process four and do the retraining process.

5) It is a training process.

6) Saving the results of the training in the form of weights for the training to be used in the application.

Table 4. Training and Testing Results

\begin{tabular}{|c|c|c|c|c|c|c|c|c|c|c|c|}
\hline No & Epoch & $\begin{array}{l}\text { Neuron } \\
\text { Number }\end{array}$ & $\begin{array}{l}\text { Mu } \\
\text { Incr }\end{array}$ & $\begin{array}{l}\text { Mu } \\
\text { Decr }\end{array}$ & $\begin{array}{c}\text { MSE } \\
\text { Training }\end{array}$ & $\begin{array}{c}\text { MSE } \\
\text { Testing }\end{array}$ & $\begin{array}{l}\text { Regr } \\
\text { Train }\end{array}$ & Regr Test & $\begin{array}{c}\text { Train } \\
\text { Accuracy }(\%)\end{array}$ & $\begin{array}{c}\text { Test Accuracy } \\
\text { (\%) }\end{array}$ & Time \\
\hline 1 & 1000 & 15 & 5 & 0.05 & $1.04 \mathrm{E}-14$ & $2.10 \mathrm{E}-03$ & 1 & 0.9937 & 86 & 88.2 & 0:00:02 \\
\hline 2 & 1000 & 15 & 5 & 0.1 & $4.704 \mathrm{E}-14$ & 0.0022 & 1 & 0.9923 & 81.4 & 79.4 & 0:00:02 \\
\hline 3 & 1000 & 15 & 5 & 1 & $8.62 \mathrm{E}-17$ & $1.90 \mathrm{E}-03$ & 1 & 0.9937 & 90.7 & 91.2 & 0:00:03 \\
\hline 4 & 1000 & 15 & 10 & 0.05 & $1.51 \mathrm{E}-15$ & $2.90 \mathrm{E}-03$ & 1 & 0.9921 & 88.4 & 88.2 & 0:00:01 \\
\hline 5 & 1000 & 15 & 10 & 0.1 & $1.37 \mathrm{E}-14$ & $2.80 \mathrm{E}-03$ & 1 & 0.9920 & 86 & 73.5 & 0:00:02 \\
\hline 6 & 1000 & 15 & 10 & 1 & $1.83 \mathrm{E}-12$ & $3.10 \mathrm{E}-03$ & 1 & 0.9891 & 88.4 & 76.5 & 0:00:01 \\
\hline 7 & 1000 & 15 & 25 & 0.05 & $2.28 \mathrm{E}-14$ & $3.30 \mathrm{E}-03$ & 1 & 0.9889 & 90.7 & 76.5 & 0:00:02 \\
\hline 8 & 1000 & 15 & 25 & 0.1 & $1.72 \mathrm{E}-15$ & $3.00 \mathrm{E}-03$ & 1 & 0.9908 & 90.7 & 82.4 & 0:00:01 \\
\hline 9 & 1000 & 15 & 25 & 1 & $1.24 \mathrm{E}-17$ & $2.30 \mathrm{E}-03$ & 1 & 0.9918 & 83.7 & 82.4 & 0:00:09 \\
\hline 10 & 1000 & 25 & 5 & 0.05 & $6.41 \mathrm{E}-15$ & $9.27 \mathrm{E}-04$ & 1 & 0.9970 & 83.7 & 94.1 & $0: 00: 14$ \\
\hline 11 & 1000 & 25 & 5 & 0.1 & $4.62 \mathrm{E}-16$ & 8.82E-04 & 1 & 0.9966 & 86 & 88.2 & 0:00:08 \\
\hline 12 & 1000 & 25 & 5 & 1 & $2.28 \mathrm{E}-14$ & $8.25 \mathrm{E}-04$ & 1 & 0.9971 & 88.4 & 94.1 & $0: 00: 57$ \\
\hline 13 & 1000 & 25 & 10 & 0.05 & $1.33 \mathrm{E}-13$ & $1.10 \mathrm{E}-03$ & 1 & 0.9969 & 86 & 88.2 & 0:00:07 \\
\hline 14 & 1000 & 25 & 10 & 0.1 & $4.95 \mathrm{E}-16$ & $9.94 \mathrm{E}-04$ & 1 & 0.9966 & 83.7 & 91.2 & 0:00:08 \\
\hline 15 & 1000 & 25 & 10 & 1 & $1.90 \mathrm{E}-14$ & 8.97E-04 & 1 & 0.9972 & 81.4 & 91.2 & 0:00:04 \\
\hline 16 & 1000 & 25 & 25 & 0.05 & $6.84 \mathrm{E}-15$ & 8.61E-04 & 1 & 0.9971 & 90.7 & 91.2 & 0:00:09 \\
\hline 17 & 1000 & 25 & 25 & 0.1 & $3.07 \mathrm{E}-14$ & $1.00 \mathrm{E}-03$ & 1 & 0.9971 & 90.7 & 97.1 & 0:00:04 \\
\hline 18 & 1000 & 25 & 25 & 1 & $1.23 \mathrm{E}-13$ & $1.00 \mathrm{E}-03$ & 1 & 0.9971 & 86 & 94.1 & 0:00:03 \\
\hline 19 & 1000 & 35 & 5 & 0.05 & $1.15 \mathrm{E}-14$ & 5.14E-04 & 1 & 0.9985 & 88.4 & 97.1 & $0: 00: 22$ \\
\hline 20 & 1000 & 35 & 5 & 0.1 & $1.59 \mathrm{E}-15$ & 4.73E-04 & 1 & 0.9983 & 90.7 & 97.1 & $0: 00: 21$ \\
\hline
\end{tabular}




\begin{tabular}{|c|c|c|c|c|c|c|c|c|c|c|c|}
\hline No & Epoch & $\begin{array}{l}\text { Neuron } \\
\text { Number }\end{array}$ & $\begin{array}{l}\text { Mu } \\
\text { Incr }\end{array}$ & $\begin{array}{l}\text { Mu } \\
\text { Decr }\end{array}$ & $\begin{array}{c}\text { MSE } \\
\text { Training }\end{array}$ & $\begin{array}{c}\text { MSE } \\
\text { Testing }\end{array}$ & $\begin{array}{l}\text { Regr } \\
\text { Train }\end{array}$ & Regr Test & $\begin{array}{c}\text { Train } \\
\text { Accuracy (\%) }\end{array}$ & $\begin{array}{c}\text { Test Accuracy } \\
(\%)\end{array}$ & Time \\
\hline 21 & 1000 & 35 & 5 & 1 & $1.14 \mathrm{E}-14$ & 4.69E-04 & 1 & 0.9982 & 83.7 & 94.1 & $0: 00: 21$ \\
\hline 22 & 1000 & 35 & 10 & 0.05 & $2.69 \mathrm{E}-16$ & 5.31E-04 & 1 & 0.9985 & 90.7 & 97.1 & $0: 00: 11$ \\
\hline 23 & 1000 & 35 & 10 & 0.1 & $4.35 \mathrm{E}-17$ & 4.70E-04 & 1 & 0.9984 & 90.7 & 97.1 & $0: 00: 23$ \\
\hline 24 & 1000 & 35 & 10 & 1 & 5.39E-15 & $5.11 \mathrm{E}-04$ & 1 & 0.9982 & 81.4 & 91.2 & $0: 00: 11$ \\
\hline 25 & 1000 & 35 & 25 & 0.05 & $1.51 \mathrm{E}-14$ & 4.68E-04 & 1 & 0.9984 & 83.7 & 97.1 & 0:00:18 \\
\hline 26 & 1000 & 35 & 25 & 0.1 & $3.37 \mathrm{E}-15$ & $6.09 \mathrm{E}-04$ & 1 & 0.9984 & 83.7 & 97.1 & $0: 00: 18$ \\
\hline 27 & 1000 & 35 & 25 & 1 & 4.97E-16 & $4.96 \mathrm{E}-04$ & 1 & 0.9984 & 83.7 & 97.1 & 0:00:18 \\
\hline 28 & 3000 & 15 & 5 & 0.05 & $3.44 \mathrm{E}-14$ & $2.00 \mathrm{E}-03$ & 1 & 0.9932 & 83.7 & 88.2 & 0:00:03 \\
\hline 29 & 3000 & 15 & 5 & 0.1 & $1.81 \mathrm{E}-15$ & $2.30 \mathrm{E}-03$ & 1 & 0.9921 & 79.1 & 88.2 & 0:00:02 \\
\hline $\begin{array}{l}\cdot \\
\cdot \\
\cdot\end{array}$ & & & & & & & & & & & \\
\hline 75 & 5000 & 35 & 5 & 1 & $3.56 \mathrm{E}-15$ & 4.94E-04 & 1 & 0.9982 & 88.4 & 94.1 & $0: 00: 35$ \\
\hline 76 & 5000 & 35 & 10 & 0.05 & $2.39 \mathrm{E}-14$ & $5.94 \mathrm{E}-04$ & 1 & 0.9984 & 86 & 97.1 & 0:00:11 \\
\hline 77 & 5000 & 35 & 10 & 0.1 & $1.03 \mathrm{E}-16$ & 5.74E-04 & 1 & 0.9978 & 79.1 & 91.2 & $0: 00: 23$ \\
\hline 78 & 5000 & 35 & 10 & 1 & $6.72 \mathrm{E}-15$ & $4.78 \mathrm{E}-04$ & 1 & 0.9984 & 86 & 94.1 & $0: 00: 17$ \\
\hline 79 & 5000 & 35 & 25 & 0.05 & $9.51 \mathrm{E}-15$ & 4.93E-04 & 1 & 0.9985 & 86 & 97.1 & 0:00:19 \\
\hline 80 & 5000 & 35 & 25 & 0.1 & 7.07E-15 & 5.14E-04 & 1 & 0.9986 & 86 & 97.1 & $0: 00: 10$ \\
\hline
\end{tabular}

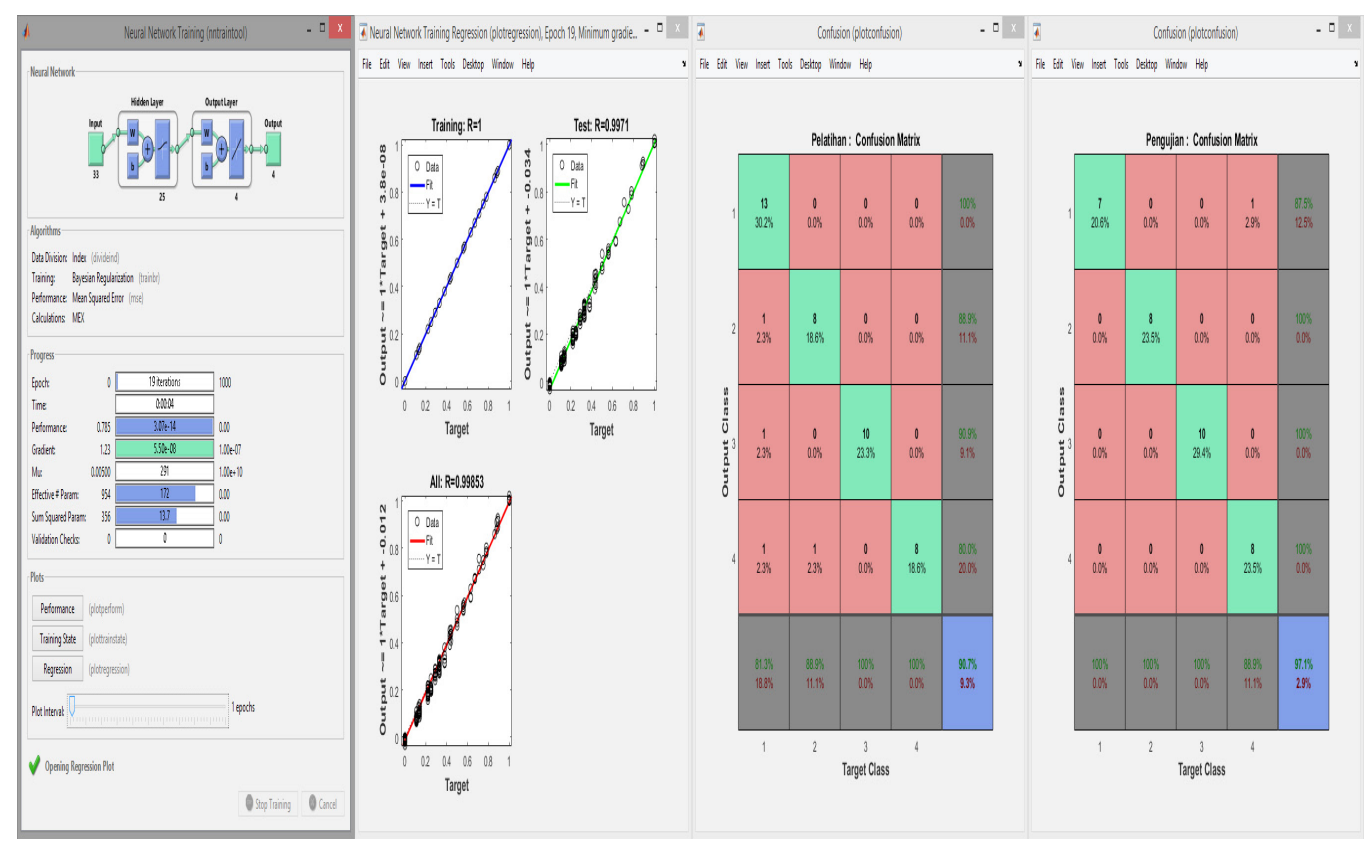

Figure 3. Training Results

Table 4 indicates the best value of the criteria with high regression values, low MSE values (close to 0 ), training accuracy values (close to $100 \%$ ) and short training time. The training parameters used in the development of architectural models are optimal training parameters. Training and regression results are shown in Figure 3 and Figure 4.

Figure 4 presents the testing regression results. Regression of artificial neural network using Matlab is how much data that does not deviate, and data that is not outside the line (fit) is non-distorted. Data that deviates from the line (fit) is data that is not recognized by artificial neural networks. The graph can also be viewed as the results of these deviations, the data (round) which is in the blue line (fit) is data that does not deviate. These data are already parallel with the line (fit). It can be concluded that the training process is successful with a regression value of 1 of 1 . 


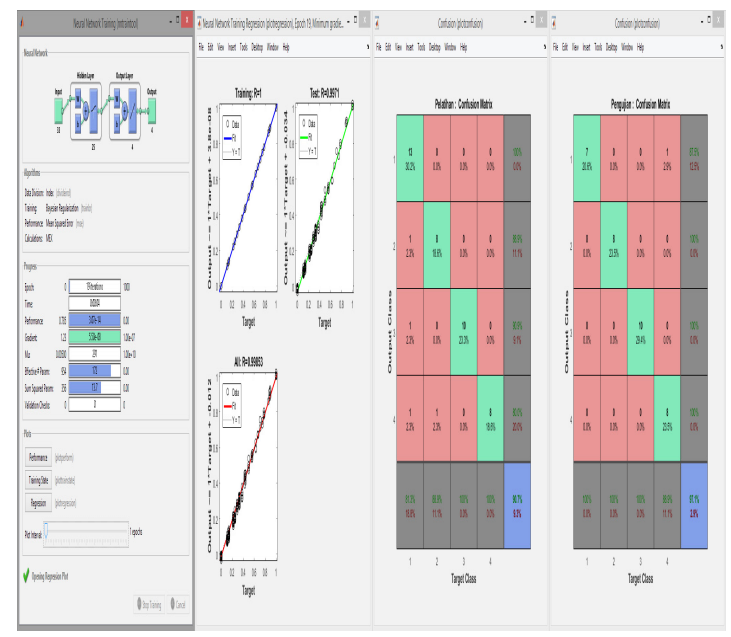

Figure 4. Testing Regression Result

Table 5. Optimal Training Parameters

\begin{tabular}{lc}
\hline \multicolumn{1}{c}{ Training Parameter } & Value Parameter \\
\hline Maximum Epoch & 1000 \\
Mu Max & 10000000000 \\
Mu increase & 25 \\
Mu decrease & 0.1 \\
Error goal & 0 \\
Max fail & 0 \\
Neuron Hidden Layer & 25 \\
\hline
\end{tabular}

The result of the training MSE is 3.07E-14, the result of the MSE Testing is $1.00 \mathrm{E}-03$, the result of the training regression is 1 , the result of the testing regression is 0.9971 and the taken time is 0:00:04 with the training accuracy level of $90.7 \%$ and the accuracy of the testing of $97.1 \%$.

The optimal training and testing parameters will be the default parameters on the training page to make it easier for users. These parameters can be seen in Table 5 .

\section{Conclusion}

The optimal value of BPNN architecture parameters for early detection of personality disorder in this research are: maximum epoch: 1000, mu max: 10000000000, mu increase: 25 , mu decrease: 0.1 , error goal: 0 , max fail: 0 , and neuron hidden layer: 25. MSE of training is 3.07E-14, MSE of testing is $1.00 \mathrm{E}-03$. The training regression is 1 , while the testing regression is 0.9971 with the taken time of 0:00:04. The accuracy of training is $90.7 \%$, and testing accuracy of $97.2 \%$, showing that the architecture of BPPN model provides very good accuracy.

Training on the multi-layer back propagation used activation function sigmoid bayesian trainbr that provides unlimited range of input value and limited range of 0 to 1 for output value. Thus, the data input has to be normalized to the range of 0 to 1 , so the data output can be adjusted into the range of input value. Further research with larger data is needed to examine further the performance of the architecture of BPNN model.

\section{Reference}

[1] M. H. America, "Personality Disorder," http:// www.mentalhealthamerica.net/conditions/ personality-disorder, America, $12^{\text {th }}$ of September 2017.

[2] A. P. Association, Diagnostic and Statistical manual of mental Disorders, fourth Edition: primary care version (DSM-IV-PC), Washington DC: American Psychiatric Association, 1995.

[3] D. Barros and A. Serafim, "Association between personality disorder and violent behavior pattern," Forensic Science International, vol. 179, no. 1, pp. 19-22, 2008.

[4] R.Arola, H.Antila, P.Riipinen, H.Hakko, K.Riala and L.Kantojarvi, "Borderline personality disorder and violent criminality in women; A population base follow-up study of adolescent psychiatric inpatients in Northen Finland," Forensic Science International, vol. 266, pp. 389-395, 2016.

[5] F. W. Chiueng, J. W. Yu, C. L. Po, H. W. Chih, F. P. Shinn and W. C. Hung, "Disease-Free Survival Assessment by Artificial Neural Networks for Hepatocellular Carcinoma patients after Radiofrequency Ablation," Journal of The Formosan Medical Association, vol. 116, no. 10, pp. 765-773, October 2017.

[6] P. Hu, "Identification of Psychological Paterns using Neural Networks Approach,” Digital 
Commons University of Nebraska Lincoln, Nebraska, 2010.

[7] E. Budianita, S. Sanjaya, F. Syafria and Redho, "PenerapanMetode Learning Vector Quantization (LVQ) untuk mementukan gangguan kehamilan trisemester I," JurnalSains, teknologi, danindustri , vol. 15, no. 2, pp. 144-151, $2^{\text {nd }}$ of June2018.

[8] T. Oktavia, D.H.Satyareni and E. Jannah, "Rancang Bangun Sistem Pakar untuk Mendiagnosis Gangguan Kepribadian Histerik Menggunakan Metode Certainty Factor," Jurnal Ilmiah Teknologi Sistem Informasi, vol. 1, no. 1, pp. 15-23, January 2015.

[9] S.A.Oyewole and O.O.Olugbara, "Product Image Classification using Eigen Colour Feature with Ensemble Machine Learning," Egyptian informatics Journal, vol. 19, no. 2, pp. 83-100, July 2018.

[10] L. M. James and J. Taylor, "Impulsivity and Negative Emotionality Associated with Subtance use Problems and Cluster B Personality in College Students," Addictive Behaviors, vol. 32, no. 4, pp. 714-727, 2007.

[11] A. A. Pradika, J. Jusak and J. Lemantara, "Sistem pakar untuk Mendiagnosis gangguan jiwa skizofrenia menggunakan metode fuzzy expert system (studi kasus RS.Jiwa Menur Surabaya)," Jurnal JSIKA, vol. 1, no. 1, 2012.

[12] H.takizawa, T.ChidaandH.Kobayashi,"Evaluating Computational Performance of Backpropagation Learning on Graphics Hardware," Electronic Notes in Theoretical Computer Science, vol. 225, pp. 379389, 2008. 